\title{
Micro RNA as Biomarkers and Tool for Target-Based Treatment in Patients with Inflammatory Bowel Diseases
}

\author{
Alexander E Berezin* and Eugene I Poplyonkin \\ Internal Medicine Department, State Medical University, 26, Mayakovskyav, Zaporozhye, Ukraine
}

${ }^{\star}$ Corresponding author: Alexander E. Berezin, Professor, MD, PhD, Internal Medicine Department, State Medical University, 26, Mayakovskyav., Zaporozhye, Ukraine 69035,Tel: +380612894585; E-mail: dr_berezin@mail.ru

Received date: January 24, 2015, Accepted date: March 20, 2015, Published date: March 27, 2015

Copyright: @ 2015 Berezin, et al. This is an open-access article distributed under the terms of the Creative Commons Attribution License, which permits unrestricted use, distribution, and reproduction in any medium, provided the original author and source are credited.

\begin{abstract}
Inflammatory bowel diseases (IBD) are common group of digestive inflammatory disorder, which characterized defective regulation of adaptive immunity. There are raised evidences that intercellular cooperation affected epithelial cells, macrophages and dendritic cells play a pivotal role in gut homeostasis. Therefore, dysregulation of cell cooperation may lead to decreased epithelial integrity and worsening of IBD. Recent pre-clinical and clinical investigations have shown that micro RNAs are involved in several pathological processes affected cell-to-cell cooperation, transferring information, tissue repair mediating, angiogenesis and neo-vascualrization. The mini review is discussed the potential role of micro RNAs as biomarkers and tool for target-based treatment in patients with inflammatory bowel diseases.
\end{abstract}

Keywords: Inflammatory bowel disease; Ulcerative colitis; Crohn's disease; Risk; microRNA

\section{Introduction}

Ulcerative colitis (UC) and Crohn's disease (CD) are the most frequently seen inflammatory bowel diseases (IBD), which have similar morphopathogenesis, but they are recognized as diseases that are distinguished sites affected the gastrointestinal tract and outside areas $[1,2]$. Although prevalence rates of IBD is variant in different countries, the chronic relapsing-remitting inflammatory disorders affecting primarily the gastrointestinal tract arises worldwide [3]. In fact, the importance of genetic risk factors in IBD development is high and it has been documented more clearly for CD than for UC [4]. Moreover, genetic risk factors added to age-related factors, female gender, obesity, current symptoms, and histopathology stages significantly associated with a reduced quality of life, body image dissatisfaction, and disability [5-8]. Therefore, patients with IBM are at significant higher risk for colorectal dysplasia, cancer, bleeding, cachexia, as well as extra intestinal manifestations, such as rheumatoid arthritis $[9,10]$.

Pathogenesis of IBD is difficult, multi faces, complex, and is not fully understood [11]. Therefore, it has been suggested that exiting genetic polymorphism affected nucleotide oligomerization domain 2 (NOD2), tumor necrosis factor (TNF)-SF15, interleukin-23-type 17 helper T-cell (Th17) genes, and appropriate autophagy genes strongly contributes in T-helper-1- and T-helper-2-dependend impairment of immune signaling processes in Crohn's disease and ulcerative colitis respectively [12-14]. Defective regulation of adaptive immunity may initiate disorders in cell-to-cell cooperation, transferring information, tissue repair mediating, angiogenesis and neovascualrization [15-17]. Indeed, crosstalk between epithelial cells, macrophages and dendritic cells plays a pivotal role in gut homeostasis [18-20]. The leading factors contributed in intercellular communication between immune cells and mediated in post-transcriptable regulation of cell function are
micro-RNA (miRNA) [21]. The aim of the mini review is summary of knowledge regarding role of miRNA in IBD development.

\section{MicroRNA: Definition and Biological Function}

miRNAs have emerged small endogenous single stranded noncoding molecules of RNA (about 15-22 nucleotides) that are able to regulate gene expression at the post-transcription level [22,23]. Currently miRNA are recognized as uniquely important regulators of a variety of physiological and pathological processes including cell growth, proliferation, differentiation, apoptosis, angiogenesis, and malignancy $[24,25]$. The process of regulation gene expression is mediated through intracellular miRNA-related degradation and translational repression of mRNA [26]. Despite miRNAs are considered ubiquitous and essential targeting specific messengers for mRNAs, one miRNA is able to target hundreds of mRNAs, and, however, one molecule of mRNA can be repressed by more than one miRNA [27]. Although intracellular mechanisms for the regulation of miRNA-mRNA interactions are universal, there is limited tissue specificity regarding transcription factors and nuclear proteins represented with miRNA [28]. Apart from intracellular miRNAs, there are wide spectrum extracellular and circulating miRNAs that are predominantly derived by microvesicules [29]. These miRNAs are able to mediate a broad range of processes affected degradation and translational repression of mRNA transcripts. Moreover, miRNAs were found as basic regulator of cellular functions including secretion and motility, which are crucial for development of both angiogenesis and malignancy. miRNAsmay contribute inhibition and/or activation of cell responses to specific stimuli by coordination and transduction of intracellular signals beyond transcript modulation. Potent function of circulating and vesicle-encapsulated miRNAs is reported in Table 1. Theoretically capacity of miRNAs to regulate systemic and localized mechanisms of signaling pathways may depend on their origin, package into microvesicles, molecular composition of cell-derived microvesicles, presentation in microvesicles protected from degradation by lipid bilayer proteins and lipids, and other factors. 
Page 2 of 5

Overall intracellular-derived and circulating miRNAs are considered mediators of cell-to-cell cross talk and they play a pivotal role in immune cell cooperation, growth signaling, apoptosis and tissue repair [30]. Interestingly, packaging of miRNAs from cells into microvesicles aimed extracellular transport can be altered by various diseases, i.e. IBD. In fact, ischemia, hypoxia, direct cell injury are consider potent stimuli of inflammatory signaling pathways promoted angiogenesis, tissue repair and malignancy.
Therefore, oxidative stress is a causal factor and key promoter of a variety of inflammatory diseases associated with apoptotic cell death by causing deregulation of related genes directly associated with miRNAs synthesis and secretion.

\begin{tabular}{|c|c|c|}
\hline Features & Circulating extracellular miRNAs & Microvesicle-encapsulated miRNAs \\
\hline Proportion in healthy subjects & $90-95 \%$ & $5-10 \%$ \\
\hline Expected proportion in IBD patients & secretion & package into vesicles \\
\hline Mechanism of delivery & free load through circulation & $\begin{array}{c}\text { vesicle encapsulation to achieving target } \\
\text { cells }\end{array}$ \\
\hline Transport modality & systemic & localized \\
\hline Targeting of signals & + & +++ \\
\hline Angiogenic potency & \pm & ++++ \\
\hline Tissue repair modality (proliferation, cell growth, differentiation) & ++ & + \\
\hline Malignancy coordination & distant & local \\
\hline Mechanism of cellular communication & & \\
\hline
\end{tabular}

Table 1: Potent function of circulating extracellular and microvesicle-encapsulated miRNAs.

However, the exact innate mechanisms of unassisted delivery of miRNAs are still poorly understood and required more investigations. Recent investigations have established that the levels of miRNAs are modulated by cell signaling mechanisms, including the bone-related morphogenetic protein signaling pathway, PI3K/Akt, and p56-MAP kinase regulators, JAK2/STAT3-dependent signaling, HypoxiaInducible Factor-1-related mechanisms, nuclear factor kappa B signaling, and etc. [28-32]. Recently in vivo and in vitro studies have presented evidence regarding that miRNA secretion and transfer may dysregulate by several signals, such as inflammatory cytokines, apoptotic intermediates and soluble apoptotic receptors [21,25,27].

\section{miRNA in Inflammatory Bowel Disease}

Recent studies have shown that miRNAs acting as negative regulators of gene expression, which are involved in intestinal inflammation among patients with IBD [33]. Therefore, miRNAs play a pivotal role in regulation of intestinal barrier dysfunction that is suitable for IBD [34,35] and they serve as biomarkers of malignancy and tumorogenesis in this patient population [36].Whether spectrum of miRNAs is useful for detecting of IBD exacerbation is not fully understood. Table 2 is reported summarized data regarding the role of miRNAs in IBD.

Alterations inmiRNA expression with overlap between different isoforms of miRNAs were identified for IBD. In fact, elevated miRNA-21 level is powerful indicator of IBD exacerbation, miRNAs-19b, -192 , and -215 were decreased in IBD, while miRNA-21, $-19 b,-192$, and -215 were found as indicators of intestinal epithelial barrier function [33]. Ayyadurai et al. [37] reported that the miRNA $23 \mathrm{~b}$ (known to be involved in IBD) was secreted and transported between cells to impose a gene-silencing effect on recipient intestinal macrophages and thereby it regulated intestinal epithelial repair. In opposite, the up-regulation of miRNA-155 (known as positive regulator of $\mathrm{T}$-cell responses) is related to colitis-associated carcinogenesis, but is irrelevant to chronic intestinal inflammation [38]. Controversially, Min et al. [39] found that miRNA-155 appears to be elevated in patients with acute UC and plays a role in the intestinal inflammation by down-regulating the expression of FOXO3a.

There are evidences that over expression of hsa-miRNA-124, hsamiRNA-146a and hsa-miRNA-221/222 mediated the crosstalk within the Toll-like receptor signaling pathway may have predictive value for progression of intestinal-related chronic inflammation to cancer [40]. In this context, it is interestingly that higher methylation levels of miRNA-124a (known to have tumor-suppressive function) associates with elevated epidemiologic risk of colitis-associated cancer development in UC patients [41]. Moreover, investigators reported that methylation status of three miRNA-124a genes (miRNA-124a-1, -2 , and -3 ) associated well with all types of intestinal neoplastic tissues. Down-regulated miRNA-133a and miRNA-143/145 was reported as biomarkers of human colorectal cancer in generally population and IBD patient cohort [42]. The spectrum of miRNAs that are involved in the pathogenesis of IBM is sufficiently wide. Whether are tissue specific miRNAs constructed specific phenotype of clinical presentation for IBD is not fully clear.

Whether is genome maps of circulating miRNAs useful for prediction of IBD development is not still clear. However, this is direction for further investigations. Overall, exosomal miRNA load assessment and exosomal miRNA profiling hold great promise for disease detection and monitoring.

Therefore, the data taken together may be helpful for risk stratification patients with IBD at several stages of the disease 
Citation: Berezin AE, Poplyonkin El (2015) Micro RNA as Biomarkers and Tool for Target-Based Treatment in Patients with Inflammatory Bowel Diseases. Biol Med (Aligarh) 7: 231. doi:10.4172/0974-8369.1000231

Page 3 of 5

development and probably as indicator for target-based therapy of stratification patients with IBD at several stages of disease IBD.

\begin{tabular}{|c|c|}
\hline miRNAs & The potent role in IBD \\
\hline Circulating miRNA-21 & Increased level associates with risk of IBD exacerbation \\
\hline Circulating miRNA 23b & Increased level associates with intestinal epithelial repair \\
\hline Circulating miRNA-155 & Increased level associates with risk of malignancy and tumorogenesis \\
\hline Microvesicle-encapsulated miRNA-155 & up-regulation was found in colitis-associated carcinogenesis and in patients with acute UC \\
\hline Microvesicle-encapsulated miRNA-192 & \multirow{4}{*}{ Biomarker of NOD2 expression } \\
\hline Microvesicle-encapsulated miR-495 & \\
\hline Microvesicle-encapsulated miR-512 & \\
\hline Microvesicle-encapsulated miR-671 & \\
\hline Circulating miRNA-124/124a & \multirow{3}{*}{$\begin{array}{l}\text { Increased level associates with risk of progression of intestinal-related chronic inflammation to } \\
\text { cancer }\end{array}$} \\
\hline Circulating miRNA-146a & \\
\hline Circulating miRNA-221/222 & \\
\hline Circulating miRNA-133a & \multirow{2}{*}{$\begin{array}{l}\text { Down-regulated level is considered a biomarker of human colorectal cancer in generally population } \\
\text { and IBD patient cohort }\end{array}$} \\
\hline Circulating miRNA-143/145 & \\
\hline Circulating miRNA-146a/146b & \multirow[t]{3}{*}{ Biomarker of cell differentiation, growth } \\
\hline Circulating miRNA-122/126, & \\
\hline Circulating miRNA-132 & \\
\hline Circulating miRNA-21 & \multirow[t]{3}{*}{ Biomarker of intestinal epithelial barrier function } \\
\hline Circulating miRNA-150, & \\
\hline Circulating miRNA-200b & \\
\hline Circulating miRNA-30c & \multirow[t]{5}{*}{ Biomarker of autophagic activity } \\
\hline Circulating miRNA-130a & \\
\hline Circulating miRNA -106b & \\
\hline Circulating miRNA-93 & \\
\hline Circulating miRNA-196 & \\
\hline
\end{tabular}

Table 2: The potent role of miRNAs in IBD development

Abbreviations: IBD: Inflammatory Bowel Diseases, UC: Ulcerative Colitis

\section{miRNA as Targeting for Therapeutic Strategy in Inflammatory Bowel Disease}

It is supposed that miRNA delivered by exosomes to specific cells by targeting with cell surface protein interaction may effect as biological regulator of metabolic processes. To achieve potential clinically significant utility circulating level of exosomes should be never less than $10^{10-12}$ exosomes $/ \mathrm{ml}$ plasma. Although there is serious criticism regarding any perspective to use of microvesicleencapsulated miRNAs, the therapeutic approaches toward regulation of function of intestinal cells in IBD patients is discussed broadly, but clinical trials regarding miRNA-related treatment program in IBD are absent [43]. However, potential translational applications of miRNAs are emerged attractive $[43,44]$.

Therefore, there are evidences clarified that chronic inhibition of histone deacetylases and controlling for synthesis of wide spectrum isoforms of histone deacetylases via miRNAs may be useful for refractory patients with IBD [45]. Potential mechanism of positive effect for histone deacetylases inhibitors (valproic acid, vorinostat and givinostat) directly relates with reduction of pro-inflammatory cytokine release, increased apoptosis of immune competent cells, and regulation of transcription factors.

Consideration among clinical implementation of obtained data is required more clinical studies with higher statistical power and increased sample size. However, the novel therapeutic approach 
associated with miRNA-related histone deacetylases inhibition appears to be attractive for clinical medicine.

\section{Conclusion}

In conclusion, we suggest that circulating miRNAs appear to be promising as possible biomarkers of IBD development and, probably, individualized indicator of response after treatment. The future of circulating miRNAs in reclassification of the patients with IBD is attractive.

This research received no specific grant from any funding agency in the public, commercial, or not-for-profit sectors.

\section{Conflict of Interest}

None declare

\section{References}

1. Isene R, Bernklev T, Høie O, Munkholm P, Tsianos E, et al. (2015) Extra intestinal manifestations in Crohn's disease and ulcerative colitis: results from a prospective, population-based European inception cohort. Scand J Gastro enterol 50:300-305.

2. Knights D, Lassen KG, Xavier RJ (2013) Advances in inflammatory bowel disease pathogenesis: linking host genetics and the microbiome. Gut 62: 1505-1510.

3. Ellinghaus D, Bethune J, Petersen BS, Franke A (2015) The genetics of Crohn's disease and ulcerative colitis--status quo and beyond. Scand J Gastroenterol 50: 13-23.

4. Bamias G, Cominelli F (2007) Immuno pathogenesis of inflammatory bowel disease: current concepts. Curr Opin Gastro enterol 23: 365-369.

5. Huppertz-Hauss G, Høivik ML, Langholz E, Odes S, Småstuen M, et al. (2015) Health-related Quality of Life in Inflammatory Bowel Disease in a European-wide Population-based Cohort 10 Years After Diagnosis. Inflamm Bowel Dis 21:337-344.

6. van der Have M, Fidder HH, Leenders M, Kaptein AA, van der Valk ME, et al. (2015) Self-reported Disability in Patients with Inflammatory Bowe Disease Largely Determined by Disease Activity and Illness Perceptions. Inflamm Bowel Dis 21:369-377.

7. McDermott E, Mullen G, Moloney J, Keegan D, Byrne K, et al (2015) Body Image Dissatisfaction: Clinical Features, and Psychosocial Disability in Inflammatory Bowel Disease. Inflamm Bowel Dis. 21:353-360.

8. Khalili H, Ananthakrishnan AN, Konijeti GG, Higuchi LM, Fuchs CS, et al. (2015) Measures of obesity and risk of Crohn's disease and ulcerative colitis. Inflamm Bowel Dis 21: 361-368.

9. Lai KK, Horvath B, Xie H, Wu X, Lewis BL, et al. (2015) Risk for colorectal neoplasia in patients with inflammatory bowel disease and mucosa indefinite for dysplasia. Inflamm Bowel Dis 21:378-384.

10. Tomasello G, Tralongo P, Damiani P, Sinagra E, Di Trapani B, et al. (2014) Dismicrobism in inflammatory bowel disease and colorectal cancer: changes in response of colocytes. World J Gastroenterol 20: 18121-18130.

11. Kaser A, Zeissig S, Blumberg RS (2010) Inflammatory bowel disease. Annu Rev Immunol 28: 573-621.

12. Hisamatsu $\mathrm{T}$, Ogata $\mathrm{H}$, Hibi $\mathrm{T}$ (2008) Innate immunity in inflammatory bowel disease: state of the art. Curr Opin Gastro enterol 24: 448-454.

13. Mueller T, Podolsky DK (2008) Nucleotide-binding-oligomerization domain proteins and toll-like receptors: sensors of the inflammatory bowel diseases' microbial environment. Curr Opin Gastro enterol 21: 419-425.

14. Abreu MT, Fukata M, Arditi M (2005) TLR signaling in the gut in health and disease. J Immunol 174: 4453-4460.
15. Taylor CT, Colgan SP (2007) Hypoxia and gastrointestinal disease. J Mol Med (Berl) 85: 1295-1300.

16. Colgan SP, Taylor CT (2010) Hypoxia: an alarm signal during intestinal inflammation. Nat Rev Gastroenterol Hepatol 7: 281-287.

17. Ortiz-Masià D, Díez I, Calatayud S, Hernández C, Cosín-Roger J, et al. (2012) Induction of CD36 and thrombospondin-1 in macrophages by hypoxia-inducible factor 1 and its relevance in the inflammatory process. PLoS One 7: e48535.

18. Annunziato F, Cosmi L, Santarlasci V, Maggi L, Liotta F, et al. (2007) Phenotypic and functional features of human Th17 cells. J Exp Med 204: 1849-1861.

19. Johansson C, Kelsall BL (2005) Phenotype and function of intestinal dendritic cells. Semin Immunol 17: 284-294.

20. Milling S, Yrlid U, Cerovic V, MacPherson G (2010) Subsets of migrating intestinal dendritic cells. Immunol Rev 234: 259-267.

21. Fernández-Messina L, Gutiérrez-Vázquez C, Rivas-García E, SánchezMadrid F, de la Fuente H (2015) Immunomodulatory role of microRNAs transferred by extracellular vesicles. Biol Cell 107::61-77.

22. Mercer TR, Dinger ME, Mattick JS (2009) Long non-coding RNAs: insights into functions. Nat Rev Genet 10: 155-159.

23. Rana TM (2007) Illuminating the silence: understanding the structure and function of small RNAs. Nat Rev Mol Cell Biol 8: 23-36.

24. Fazi F, Nervi C (2008) MicroRNA: basic mechanisms and transcriptional regulatory networks for cell fate determination. Cardiovasc Res 79: 553-561.

25. Raisch J, Darfeuille-Michaud A, Nguyen HT (2013) Role of microRNAs in the immune system, inflammation and cancer. World J Gastroenterol 19: 2985-2996.

26. Bartel DP (2004) MicroRNAs: genomics, biogenesis, mechanism, and function. Cell 116: 281-297.

27. Ambros V (2004) The functions of animal microRNAs. Nature 431: 350-355.

28. Hata A, Kang H (2015) Functions of the bone morphogenetic protein signaling pathway through microRNAs (review). Int J Mol Med 35: 563-568.

29. Turchinovich A, Weiz L, Burwinkel B (2012) Extracellular miRNAs: the mystery of their origin and function. Trends BiochemSci 37: 460-465.

30. Movafagh S, Crook S, Vo K (2015) Regulation of hypoxia-inducible factor-1a by reactive oxygen species : new developments in an old debate. J Cell Biochem 116: 696-703.

31. Joilin G, Guévremont D, Ryan B, Claudianos C, Cristino AS, et al. (2014) Rapid regulation of microRNA following induction of long-term potentiation in vivo. Front Mol Neurosci 7: 98.

32. Zhai H, Fesler A, Ju J (2013) MicroRNA: a third dimension in autophagy. Cell Cycle 12: 246-250.

33. Wu F, Dong F, Arendovich N, Zhang J, Huang Y, et al. (2014) Divergent influence of microRNA-21 deletion on murine colitis phenotypes. Inflamm Bowel Dis 20: 1972-1985.

34. Zhang L, Cheng J, Fan XM (2014) MicroRNAs: New therapeutic targets for intestinal barrier dysfunction. World J Gastroenterol 20: 5818-5825.

35. Cichon C, Sabharwal H, Rüter C, Schmidt MA (2014) Micro RNAs regulate tight junction proteins and modulate epithelial/endothelial barrier functions. Tissue Barriers 2: e944446.

36. Zhang L, Fan XM (2014) The pathological role of microRNAs and inflammation in colon carcinogenesis. Clin Res Hepatol Gastroenterol.

37. Ayyadurai S, Charania MA, Xiao B, Viennois E, Zhang Y, et al. (2014) Colonic miRNA expression/secretion, regulated by intestinal epithelial PepT1, plays an important role in cell-to-cell communication during colitis. PLoS One 9: e87614.

38. Singh UP, Murphy AE, Enos RT, Shamran HA, Singh NP, et al. (2014) miR-155 deficiency protects mice from experimental colitis by reducing T helper type 1/type 17 responses. Immunology 143: 478-489.

39. Min M, Peng L, Yang Y, Guo M, Wang W, et al. (2014) MicroRNA-155 is involved in the pathogenesis of ulcerative colitis by targeting FOXO3a. Inflamm Bowel Dis 20: 652-659. 
Citation: Berezin AE, Poplyonkin El (2015) Micro RNA as Biomarkers and Tool for Target-Based Treatment in Patients with Inflammatory Bowel Diseases. Biol Med (Aligarh) 7: 231. doi:10.4172/0974-8369.1000231

Page 5 of 5

40. Li W, Han W, Zhao X, Wang H (2014) [Changes of expression of miR-155 in colitis-associated colonic carcinogenesis]. Zhonghua Zhong Liu ZaZhi 36: 257-262.

41. Ueda Y, Ando T, Nanjo S, Ushijima T, Sugiyama T (2014) DNA methylation of microRNA-124a is a potential risk marker of colitisassociated cancer in patients with ulcerative colitis. Dig Dis Sci 59: 2444-2451.

42. Josse C, Bouznad N, Geurts P, Irrthum A, Huynh-Thu VA, et al. (2014) Identification of a microRNA landscape targeting the PI3K/Akt signaling pathway in inflammation-induced colorectal carcinogenesis. Am J Physiol Gastro intest Liver Physiol 306: G229-243.

43. Kalla R, Ventham NT, Kennedy NA, Quintana JF, Nimmo ER, et al. (2015) Micro RNAs: new players in IBD. Gut 64: 504-517.

44. Chapman CG, Pekow J (2015) The emerging role of miRNAs in inflammatory bowel disease: a review. Therap Adv Gastro enterol 8: 4-22.

45. Felice C, Lewis A, Armuzzi A, Lindsay JO, Silver A (2015) Review article: selective histone deacetylase isoforms as potential therapeutic targets in inflammatory bowel diseases. Aliment Pharmacol Ther 41: 26-38. 